\title{
Un acercamiento al concepto de comunidad en el universo tradicional negroafricano
}

\section{Understanding the concept of community in the traditional black-African universe}

\author{
LOUIS VALENTIN MBALLA \\ Universidad Autónoma de San Luis Potosí, México
}

Resumen: El objetivo de este artículo es edificar un marco de comprensión de la realidad comunitaria en África subsahariana tradicional. Los antecedentes del contenido epistemológico del concepto de comunidad muestran que las aportaciones varían en función de los parámetros de análisis de cada autor. Asimismo, se asume que la comprensión de la realidad comunitaria en el universo negroafricano no es posible si no se fundamenta en las variables de la estructura socioantropológica del universo negroafricano: la persona, la familia, el clan, la tribu, la etnia y las religiones tradicionales ancestrales. A través de un análisis de esas variables, se llega a la conclusión de que es necesario guardar las distancias respecto al actual estadocentrismo para repensar los modos de organización comunitaria en África subsahariana tradicional, en toda su diversidad y complementariedad.

Recepción: 28 de enero de 2019. / Aceptación: 3 de mayo de 2019. 


\begin{abstract}
etnia.
Palabras clave: comunidad; negroafricano; familia; clan; tribu/
\end{abstract}

Abstract: This article seeks to build a framework for understanding the community reality in traditional sub-Saharan Africa. The background of the community concept's epistemological content shows that the existing contributions vary, depending on each author's analytic parameters. Any understanding of the community reality in black Africa needs to be based on the socioanthropological variables of the black-African universe: the individual, the family, the clan, the tribe/ethnicity, and the ancestral religions. By analyzing these variables, the author concludes that it is necessary to keep a distance from the current state-centric paradigm and to rethink approaches to community organization in traditional sub-Saharan Africa, in all its diversity and complementarity. ity.

Keywords: community; black African; family; clan; tribe/ethnic-

En tant que concept scientifique, le terme "communaute" n'a aucune valeur; en tant qu'instrument pour la création d'un imaginaire social, il occupe assurément une place fondamentale, et sans doute est-il destiné à se perpétuer.

Busino, 1993.

\title{
Introducción
}

El análisis que se emprende del contenido epistemológico del concepto de comunidad en el universo negroafricano se inscribe en la lógica de búsqueda de herramientas para comprender la dinámica funcional de la sociedad africana. Desde un particular punto de vista, la comunidad en África subsahariana tradicional ${ }^{1}$ consiste en un esfuerzo de edificación gradual de la con-

${ }^{1}$ Lo tradicional aquí hace referencia a la cultura ancestral que ha ido transformándose a lo largo de la historia de todo el continente. En realidad, las tradiciones 
fianza, cooperación y solidaridad entre actores esencialmente diferentes, que promueve una variedad de intercambios entre sí. En la literatura hay una evidente controversia en cuanto al uso de los términos África subsabariana, África negra, África subsabariana tradicional, etc., que, aunque puedan significar lo mismo en el plano semántico, no lo hacen en el político. Hoy en día, África subsabariana sería la denominación "políticamente correcta", ya que remite a una configuración geopolítica e histórica que se sitúa más allá del rasgo racial, pues, como se sabe, en Sudáfrica, por ejemplo, hay sudafricanos de raza blanca. En este artículo uso los términos negroafricano/negroafricana y África negra tradicional, como postura propia para puntualizar la dinámica de construcción comunitaria en esa zona.

El objetivo es reconceptualizar la realidad comunitaria en África negra tradicional según la hipótesis de que cada proyecto que emprende el hombre hoy en día debería establecerse en una idea de cambio y progreso, aun cuando predomine la tendencia a mantener las cosas como están: la resistencia al cambio. Esta perspectiva está fuertemente vinculada a la idea de acción, y cada acción tiene consecuencias, resultados e impactos. La noción de comunidad como espacio de "acción en conjunto" no escapa a la lógica de camino hacia el cambio y el progreso. En este sentido, se intenta dar cuenta del modo en que la comunidad, hoy por hoy, es factor de un rediseño o de reafirmación de las identidades y los polos de identificación, tanto para sus miembros como para aquellos que la miran desde afuera.

La pregunta que guía este artículo es: ¿qué variables han de tomarse en cuenta para comprender la noción de convivencia comunitaria en el universo negroafricano? Al tratar

\footnotetext{
negroafricanas contienen elementos consignados en dos planos: i) el teórico: donde opera la cosmología (es decir el conjunto de representaciones del mundo que determinan los principios generales, las reglas formales y los valores que han de regir la vida cotidiana) y donde se encuentran las justificaciones supremas de las acciones llevadas a cabo por los individuos en la vida cotidiana, y ii) el práctico: aquí se sitúan las costumbres propiamente dichas, surgidas de la puesta en práctica de los principios intrínsecos en la cosmología.
} 
de contestarla, Wilhelmy (1988) consideró que la noción de comunidad en África negra se entiende fundamentalmente a través del conjunto de valores e intereses compartidos en los diferentes niveles de la estructura socioantropológica del universo negroafricano: la persona, la familia, el clan, la tribu, la etnia y las religiones tradicionales ancestrales. ${ }^{2}$

La aportación de Wilhelmy, que comparto ampliamente, encuentra su sentido en lo que plantean autores como Cheik Anta Diop (1974), Adonon (2003), Ki-Zerbo (2003), M'Bokolo (1980), Guérin (2004), Cabral (1975), Eberhard (2002) o Alliot (2000). Este último, por ejemplo, considera que una construcción comunitaria original se elabora con base en tres mecanismos esenciales: compartir una misma vida, compartir la totalidad de las especificidades y compartir una estructura de toma de decisiones (Alliot, 1985). Es precisamente alrededor de esas variables como se puede establecer un vínculo social indispensable para la convivencia comunitaria en África negra tradicional.

En un primer momento, el artículo retoma algunos enfoques del análisis de la noción de comunidad; en ese sentido, destaca que dicho concepto, por su volatilidad e hiperpolisemia, se ha vuelto objeto de controversias en la arena poliparadigmática de las ciencias sociales. En un segundo instante, se conceptualiza la comunidad en África negra tradicional a través de tres variables: persona, familia y clan. Aquí se destaca que el orden de los cambios en las tradiciones negroafricanas va de la persona humana hacia la sociedad, es decir, a contracorriente de los modelos de administración colonial (democracia, cristianismo, economía de mercado, etc.) impuestos en África por el colonizador, en los que los cambios tienden a realizarse en sentido contrario: de la sociedad hacia la persona humana. En realidad, varios pensadores africanos, con base en la organización de la familia y del Estado precolonial en África, en las

${ }^{2}$ En este trabajo no se aborda la variable de las religiones tradicionales ancestrales, por su inmensa complejidad. 
concepciones religiosas, filosóficas y éticas tradicionales, coinciden en lo pertinente de la convivencia comunitaria. Es lo que Cheikh Anta Diop (1974) llamó "la unidad histórica de Africa”. En un tercer momento, se considera el paradigma étnico-tribal como la plataforma del dinamismo comunitario en África negra tradicional, y sobresale que se caracteriza por un alto grado de etnicidad, entendida como cualidad étnica que implica la afiliación y la conciencia de pertenencia a un grupo étnico-cultural. Estos tres momentos esenciales me permiten concluir que la noción de comunidad en el universo negroafricano se erige sobre toda la herencia sociocultural, económica y política de África negra tradicional.

\section{La dimensión polisémica del concepto de comunidad: problemas de definición}

El concepto de comunidad, por su carácter fundamentalmente dinámico, es controversial, lo que amplía su polisemia. Hoy se habla de comunidades indígenas, comunidades vecinales, de la comunidad islámica, de la Comunidad Europea, de la comunidad católica, de las comunidades virtuales, de las comunidades científicas, así como de la comunidad internacional, como si la palabra comunidad fuera autoexplicable y no se necesitara reflexionar más sobre su significado. Algunas de estas agrupaciones, como las redes virtuales, las redes de activistas, las redes de organizaciones de base, las organizaciones no gubernamentales y las organizaciones de base mismas (grassroot organizations), también se valen del calificativo "comunidad", que remite a formas de organización e interacción basadas en relaciones de interés mutuo.

Por lo pronto, Busino (1993, p. 125) estimó que, en su dimensión meramente científica, ${ }^{3}$ el concepto de comunidad no

${ }^{3}$ Al utilizar la expresión "en tanto que concepto científico el término 'comunidad" para referirse al contenido epistemológico del concepto de "comunidad", Busino pone en exergo un acercamiento conceptual basado en las metodologías y las téc- 
tiene ningún valor, pero como herramienta para la creación de un imaginario social ocupa un lugar esencial y, sin duda, está destinado a perpetuarse. También plantea la paradoja y la complejidad que implica cualquier intento serio de investigar el significado exacto de ese concepto tan de moda en las ciencias sociales.

Algunos sociólogos franceses han subrayado la dificultad de definir este concepto. Boudon y Bourricaud (1986) hablan de las confusiones que provoca, mientras que Louis Moreau de Bellaing (1990, p. 87) estima que tales dificultades se deben a su "hiperpolisemia". Esta constatación no es propia de los investigadores franceses. En Alemania, desde 1931, Theodor Geiger (1932) propuso que el término "comunidad" fuera simple y sencillamente borrado del vocabulario de las ciencias sociales porque sus ambigüedades y equívocos son importantes y profundos. Por su parte, René König habla del papel nefasto que dicho "concepto fundamental" ha desempeñado en las ciencias sociales en Alemania (Guérin, 2004, p. 2).

Una consideración similar se ha manifestado en los círculos de investigación anglosajones. Asimismo, al referirse a ese concepto, David W. Minar y Scott Greer (1969, p. 9) hablan de una abstracción compleja y generalmente carente de sustento real y material que, por lo mismo, debilita los esfuerzos de investigación en ciencias sociales. En este sentido, el sociólogo norteamericano George A. Hillery Jr. (1955) recolectó 94 definiciones del concepto utilizadas en la sociología de su país y las equiparó en un artículo para encontrar sus puntos comunes con la esperanza de identificar las características centrales que rodean la idea de comunidad. Este intento, según el propio autor, fue un "fracaso útil: después de haber confrontado todas esas definiciones, resulta que no hay un argumento sólido para apoderarse del concepto de comunidad" (Hillery, 1982, p. 98).

nicas científicas que establecen relaciones causa-efecto en el funcionamiento de la comunidad. 
En el mismo registro, Poplin (1972) consideró que el concepto de comunidad es

uno de los términos portadores de más confusiones que se utilizan en ciencias sociales en general, y en la sociología en particular, ya que, en vez de facilitar la comprensión de la dinámica social a los investigadores -y sobre todo a los estudiantes-, los confunde aún más cuando intentan distinguir los diferentes tipos de comunidades.

En Gran Bretaña, Scherer (1972) se conformó con tildarlo de desordenado, difícil y portador de equívocos, de tal modo que los constantes esfuerzos por definirlo han llevado a más desconcierto y menos aclaraciones.

Estas lecturas indican que el concepto de comunidad se distingue por su carácter heterogéneo, ambiguo, confuso y a veces contradictorio. Sin embargo, a pesar de esta elasticidad o complejidad, no sólo es de suma importancia en el presente artículo, sino que seguirá siendo de constante interés en las ciencias sociales. Esto significa que no puede abarcar los mismos hechos en diferentes épocas y lugares. Sus contenidos, entornos y atributos deben, inevitablemente, transformarse para no volverse por completo obsoletos y fuera de contexto. De hecho, los avatares de la realidad comunitaria imponen esta constante renovación e innovación en las ideas, los métodos y los modos de acercamiento racional del concepto de comunidad. Sin embargo, forjar una nueva franquía conceptual o metodológica, y redimensionar un concepto existente en otros paradigmas (como ocurre con el concepto de comunidad), no implica que los métodos de acercamiento y los significados de dicho concepto en esos paradigmas no sean válidos o carezcan de contenido epistemológico.

Así pues, la noción de comunidad, al igual que cualquier otro concepto básico en ciencias sociales, debe ser ubicada siempre en un contexto sociocultural e institucional preciso, tomando en cuenta su dimensión espaciotemporal. Es decir, como lo plantea Passeron (1991, p. 45), dicho concepto puede encontrar su lugar en diferentes paradigmas de las ciencias 
sociales sin que una u otra de sus acepciones sea forzosamente superior o inferior a las demás. Esto permite retroalimentar constantemente sus contenidos y sus significados históricos. Asimismo, es necesario ver la dimensión polisémica del concepto de comunidad no como una limitante, sino como un valor o corolario positivo de una adaptación permanente a las realidades descritas o analizadas (Passeron, 1991, p. 45). En este sentido, esta polisemia es resultado no de una debilidad constitutiva del concepto, sino de su riqueza, ya que remite a la multiplicidad y la complejidad de las realidades sociales y organizacionales. Se trata de comprender que, al hablar de comunidad, nos ubicamos ante formas de organización sobre las que se ha teorizado ampliamente en los grandes ejes paradigmáticos de las ciencias sociales, pero casi siempre en forma fragmentaria.

\section{La comunidad: una manifestación de las variables culturales en África subsahariana}

Las sociedades tradicionales negroafricanas comparten los arquetipos diferenciación/complementariedad y pluralidad/ unidad con varias otras sociedades animistas del planeta (Adonon, 2012, p. 13). Con base en ello, es científicamente valioso fincar las bases de una concepción de "comunidad" en África tradicional, lo que Eberhard (2002, p. 307) denominó "un nuevo paradigma comunitario".

En este sentido, Alliot (2000) plantea que la conceptualización original de la comunidad en África tradicional se fundamenta en tres mecanismos esenciales:

1. Compartir una misma vida.

2. Compartir la totalidad de las especificidades.

3. Compartir una estructura de toma de decisiones.

Alrededor de estos tres mecanismos se puede establecer un vínculo social de tipo neocomunitario. Compartir es a la 
vez diferenciar y unificar, definir los límites socioculturales y concebir lo que unos y otros tienen en común o de diferente, para establecer reglas de juego apegadas al consenso con el fin de que se construya una comunidad solidaria. Asimismo, hace falta una verdadera cura de desintoxicación para salir de los avatares del estadocentrismo, del sociocentrismo, del estadojuridismo y del estatismo occidental (Sanz, 2010; Laako, 2014; Gutiérrez, 2017), ya que son las principales causas del olvido de "lo local", donde se encuentra precisamente esta noción multidimensional de "compartir" (Mballa, 2011a). Es, pues, posible - guardando las distancias respecto a dichos paradigmas- repensar la noción de comunidad en su diversidad y complementariedad con nuevos referentes apegados a la pluralidad.

Una pregunta interesante es: ¿cuáles son, entonces, los rasgos de un paradigma comunitario en la experiencia de África tradicional? Para contestarla, se puede uno apoyar en los tres mecanismos mencionados por Alliot para comprender que esos rasgos se encuentran no en las similitudes o semejanzas, sino en la triple noción de "compartir" (una misma vi$\mathrm{da}$, la totalidad de las especificidades y una estructura de toma de decisiones). Acerca del mecanismo de compartir la totalidad de las especificidades, éste responde a un modelo claro de complementariedad, y todas las especificidades socioculturales de los negroafricanos adquieren cohesión en ella. La especificidad de cada actor individual, y colectivamente hablando, es necesaria y fundamental para la acción del otro; allí está la base del análisis de cualquier comunidad en general, y también de África tradicional.

Al comparar esta perspectiva con la de los mitos sobre la construcción de la sociedad occidental, edificados sobre la igualdad, la equidad y la homogeneidad, el propio Alliot (2003, p. 62) subraya que

gran parte de los mitos sobre la fundación de las comunidades muestra que unos actores semejantes no pueden crear una comunidad si previamente no son diferenciados. Asimismo, la comunidad es un conjunto 
de elementos diferentes, interdependientes y jerarquizados; y al estar así, la unidad de la comunidad viene de la valoración de las diferencias [...] y esta perspectiva endógena se opone a los planteamientos de ciencia política occidental que ve las comunidades tradicionales como un conjunto de estructuras carentes de poder, o con un poder difuso, confuso y limitado.

Esta consideración es de suma importancia para comprender las derrotas ${ }^{4}$ de la democracia neoliberal occidental en África subsahariana. En efecto, en las comunidades tradicionales africanas no hay un poder único que monopoliza las directrices del quehacer político, religioso, institucional y económico tal y como lo hace el Estado westfaliano; más bien, este poder se genera de modo continuo por la interacción complementaria de una multitud de poderes diferentes entre sí.

En cuanto a la estructura de toma de decisiones, se trata ante todo de un espacio de autorregulación inherente o endógena a la dinámica comunitaria en África tradicional. Esta estructura se encuentra en las costumbres africanas (forma de resolver los conflictos, por ejemplo). Este ideal de autorregulación, además del pluralismo que caracteriza la organización social en África negra tradicional, le confiere al paradigma de comunidad una dimensión de responsabilidad. Esto significa que la comunidad, así como los diferentes grupos e individuos que la conforman,

${ }^{4}$ Desde las supuestas independencias (finales de los cincuenta-inicios de los sesenta) hasta hoy, los Estados africanos debieron hacer frente a una espectacular oleada de conflictos, acompañados de una crisis económica generalizada. Esas crisis, como muestra de las derrotas del modelo de la democracia neoliberal, condujeron al fracaso de casi todas las instituciones políticas, socioeconómicas y financieras del continente. Los ejemplos de Camerún, Nigeria, Congo, Burkina Faso y Liberia, entre otros, al inicio de los años noventa, recuerdan dicha situación de inestabilidad (ciudades paralizadas, elecciones cuestionadas, golpes de Estado) (Mballa, 2008). La tragedia genocida de Rwanda en 1994 marcó el inicio de un largo episodio de violencia en toda la región de los Grandes Lagos, violencia que culminó con el inicio del famoso conflicto de los Grandes Lagos, y que Breackman llamó la primera guerra mundial africana (Verschave, 1995, p. 10). En pocas palabras, el modelo de democracia neoliberal occidental fracasó en toda África. Adotevi (1996, p. 83) estimó que este fracaso se explica por la superficialidad y la artificialidad de las fundaciones sobre las cuales se edificó el Estado africano poscolonial. 
son responsables de su porvenir, que no dejan de recrear, reinventar y redimensionar continuamente, ya que no cuentan con ninguna entidad externa o exógena que lo haga por ellos. Esto también se opone al modelo de las sociedades "modernas”, en las que el Estado desempeña este papel de recreación, desresponsabilización, reinvención y redimensionamiento del porvenir de los ciudadanos.

Otro rasgo esencial del modelo de comunidad en África tradicional es la lógica funcional en la cual se inscribe y que le otorga un carácter dinámico; esto se refleja en las costumbres que establece el binomio deberes-derechos, el cual moldea el comportamiento de los individuos y los grupos socioculturales que conforman la geometría comunitaria. En este sentido, algunas investigaciones de Le Roy sobre la organización comunitaria de los wolof (Senegal), los biafra (Nigeria), los ewondo (Camerún) y los mandinga (Gambia, Guinea, Guinea-Bisau, Mali, Sierra Leona, Liberia, Burkina Faso y Costa de Marfil) sacan a la luz cuatro rasgos que ilustran perfectamente el modelo de comunidad en África subsahariana tradicional. En primer lugar, sobresale el pluralismo inherente a esas comunidades en todos los ámbitos (económico, político, jurídico...); desde luego, se vuelve absurdo pensar que el carácter pluriétnico y multicultural de la sociedad africana es un obstáculo para la construcción comunitaria. En segundo lugar, destaca su lógica funcional basada en un tipo de axiología empírica que determina la explotación de los lazos de parentesco. En tercer lugar, destaca el pragmatismo que caracteriza los modos de negociación y de toma de decisiones. En fin, resalta el ideal comunitario en los métodos de resolución de conflictos (Le Roy, 1999, pp. 315-317). Esos elementos son el denominador común de casi todas las comunidades tradicionales en África subsahariana tradicional.

Con lo que precede, nos encontramos ante un paradigma de comunidad original que podría ser el ecosistema de valores o una praxis de la dinámica intercultural. Aquí sacamos un paradigma comunitario con base en la observación, la lectura y 
la comprensión del modo de funcionamiento de las sociedades tradicionales africanas. La profundización de esta perspectiva puede lograrse mediante un análisis puntual de las estructuras sociales africanas, que, sin duda, deberían conformar el conjunto de pilares para conceptualizar la comunidad en el universo negroafricano. En efecto, en África negra tradicional la concepción de la comunidad se apoya en elementos que constituyen el armazón de las estructuras sociales africanas. Aquí la comunidad no se entiende si no se toman en cuenta sus elementos constitutivos, que, si en lo conceptual son los mismos que en la sociedad occidental, en lo práctico tienen diferencias sustanciales. Se trata de la persona humana, de la familia, del clan, de la tribu, de la etnia y de las religiones tradicionales ancestrales, como se observa en la figura 1.

\section{FIGURA 1. Estructura social original de África negra tradicional}

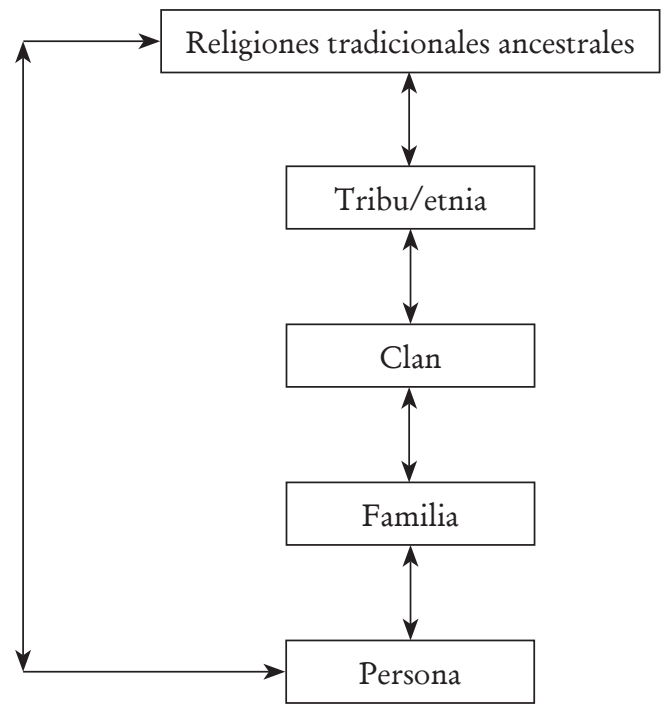

Fuente: elaboración propia con orientación del texto de Wilhemy, 1998. 


\section{Visión negroafricana de la persona}

La noción del hombre, que entre los griegos fue de carácter esencialista, tuvo un acercamiento cíclico en la historia de la filosofía desde la premisa de que la persona humana es una realidad material proveniente de un proceso evolutivo de la naturaleza, es decir, una materia complejamente organizada. Por poseer razón y conciencia, la persona ha sido catalogada como sustancia individual de naturaleza racional. Asimismo, el pensamiento filosófico eurocéntrico ha acudido a otros conceptos para tratar de comprender esta sustancia, de tal forma que, en la teoría del conocimiento, los conceptos "sujeto" y "yo" han servido para representarla como el conocedor de la realidad. Esta perspectiva le ha conferido a la noción del "yo" un carácter esencialmente individualista en el que cada individuo parece un ente aislado que comparte casualmente algunos de sus atributos con los demás.

En África subsahariana, persona es un sustantivo que significa "ser miembro de la humanidad" (Mveng, 1966, p. 45). En este sentido, Laleye (1970) plantea que en África negra "persona" no es un concepto puro en el sentido filosófico eurocéntrico, sino que se sustenta en la acción comunal en la que otros participan. Desde esta perspectiva, los rasgos significativos de la identidad cultural en África subsahariana estarían regulados por la ubicación del sujeto que se autoidentifica (comunitariamente hablando); esto quiere decir que la dinámica funcional de esta regulación lleva a la formación de un eje que va desde lo más cercano (individuo, familia, clan, etc.) hasta lo más complejo (Estado-nación).

Desde luego, destaca la evidencia de que la unidad es un principio básico de la antropología transmitida por las cosmologías tradicionales negroafricanas en general. Lejos de buscar la negación de la autonomía individual, el principio de unidad se apoya precisamente en la noción de persona humana o del "individuo" concebido como "ser comunitario" (Mballa, 2011b, p. 243). El mismo principio está motivado por la convicción de 
que la dignidad y la felicidad del individuo exigen que se mantenga su condición de ser unido a sí mismo, al mundo visible y al mundo invisible. De este modo, el concepto de persona en África subsahariana se sustenta en la regulación del universo o del cosmos, cuya realidad existencial se manifiesta en la unidad de sus componentes de las dimensiones visible e invisible.

Varios filósofos africanos han delineado la búsqueda de una identidad del negroafricano; en su mayoría han llegado a la conclusión de que se autoidentifica muriendo en sí mismo para renacer en el otro (Azombo, 1971, p. 32). Esto significa que el negroafricano no asimila en su personalidad las dinámicas socioculturales, sino que éstas se asimilan a él y viven en simbiosis con el Otro en un proceso de conocimiento y reinvención permanente. Aquí, sujeto y objeto están dialécticamente confrontados en un acto de conocimiento que, según Senghor (1964, p. 259), es “acto de afecto, de adhesión y de devoción”. En este sentido, Senghor opuso el cogito cartesiano "pienso, luego existo" a su versión epistemológica del negroafricano: "yo siento al Otro, bailo con Él y luego existo" (p. 259). Obviamente, esa afirmación de Senghor ha sido objeto de varias críticas; algunos de sus detractores puntualizan que con esa visión senghoriana del yo, el negroafricano es pura emoción sin ningún tinte de racionalidad. Senghor simplemente argumentó que en la vivencia del negroafricano no existe la posibilidad de separar la emoción negra de su racionalidad, y que ambas se encuentran unidas de forma mística. Este planteamiento ilustra perfectamente una concepción filosófica del negroafricano en la que la razón de ser de la persona es la existencia y la presencia del otro. Fanon (1961, p. 139) lo explica más empíricamente al considerar que un hombre aislado encontrará más obstáculos al querer resolver un problema solo, pero la familia, el clan o la comunidad (como esferas de construcción de la identidad individual en África negra) lo resolverán con mayor eficiencia.

El proverbio bantú "Todo crece junto en mutua causalidad y todos compartimos la responsabilidad" se inscribe en esta misma lógica explicativa de la dimensión comunitaria del 
individuo en África negra; significa que en los mecanismos de realización y emancipación del negroafricano no hay un solo actor, más bien "somos todos indispensables". Por lo tanto, Amílcar Cabral (1975, p. 345) habla de la "supremacía de la vida comunitaria sobre la vida individual en África negra subsahariana”. Ibrahim Sow (1977, p. 59), por su parte, considera que la individualidad negroafricana es una totalidad construida por tres ejes principales: el ancestro, la familia y la comunidad, los cuales definen la naturaleza de la persona humana en el universo negroafricano. Aquí se considera que la totalidad individual se integra de modo natural en una totalidad ordenada según las leyes transmitidas de generación en generación por el orden ancestral en cada comunidad. Asimismo, en su intimidad, la individualidad del negroafricano se construye a través de las relaciones fundamentales entre esos ejes, que son un marco institucional innegable en África negra.

El ejemplo de los pueblos de los Estados actuales de la región de los Grandes Lagos en África central lo ilustra perfectamente. Allí, la diferencia de sexo entre el varón, yakala (República Democrática del Congo-Ruanda-Burundi, Uganda), y la mujer, nkento, se inscribe en la lógica y el ideal de la fusión sexual según la cual el Ser Perfecto (Dios) no es ni hombre ni mujer, sino que es total, perfecto, cerrado (clos), hermafrodita (Balandier, 1955, p. 313). La escisión en dos (hombre-mujer) es concebida como un sufrimiento en el que el hombre busca de manera solitaria sus atributos femeninos, y la mujer, sola, sus atributos masculinos (Faïk-Nzuzi, 1993, p. 27). Aquí, la estructura de esta indiferenciación relativa está reforzada con la idea de que la fecundidad de la mujer maximiza las capacidades masculinas del hombre, de modo que los dos seres se mueven en términos de "complementariedad absoluta" ( $\mathrm{Ha}-$ genbucher, 1973, p. 35).

La misma lógica se ha forjado en cuanto a la concepción africana de las generaciones, ya que el hijo se percibe como un todo dentro de la estructura del linaje. Lo más relevante en esta perspectiva es que se les dice "papá" y "mamá" a todos los 
hombres y todas las mujeres, independientemente de los lazos de parentesco (Mappa, 1998, p. 25). En otras palabras, todos los hombres y todas las mujeres son asimilados a las figuras del padre y de la madre. Lo que en Occidente se conoce como "primos", "tíos" y "abuelos", en África negra tradicional son sencillamente "padres", "madres" y "hermanos", porque en la mayoría de las lenguas africanas no existen los otros términos. Esta individualidad del negroafricano se socializa en primera instancia en la institución familiar.

\section{El perfil de la familia en África subsahariana: esfera de socialización del individuo}

En África, como en cualquier parte del mundo, la familia es el lugar insustituible para formar al hombre-mujer completo, para configurar y desarrollar la individualidad y la originalidad del ser humano. En África negra subsahariana, la familia es una comunidad de personas establecidas generalmente mediante "arreglos" entre los progenitores de la familia del marido y de la "esposa", en la que nace y crece la vida en términos de entidad, referencia e identidad de la persona (Ocholla-Ayayo, 1999; Valdivia, 2008; Reynés, 2012; Castañeda, 2016). El vínculo de la sangre da paso a otros vínculos más espirituales: respeto, amor, felicidad.

La familia negroafricana engloba a todos sus miembros (hermanos, abuelos, primos, tíos, bisabuelos, tatarabuelos...), entre los cuales tiene que haber gran solidaridad. Sin embargo, es importante mencionar que en la actualidad está cada vez más presionada por la abundancia de factores que han ido rompiendo su estructura y su concepción tradicional. Asimismo, la cohesión de su organización oscila entre los factores y las exigencias de la cultura extraafricana y su estructura tradicional. En este sentido, Minuchin (1979, p. 66) consideró que los cambios que se operan en África parten de la sociedad en su conjunto hacia la unidad mínima que constituye la familia, 
aunque nunca podrán destruir el núcleo de la familia africana tradicional. Sin embargo, es relevante mencionar que el encuentro tanto contradictorio como complementario entre tradición y modernidad ha propiciado la emergencia de una familia negroafricana más dinámica marcada por una constante integración de esta tensión bipolar. Al respecto, Tsala-Tsala (1989, p. 115) considera que los factores tradicionales subsisten en el imaginario y los comportamientos de la familia africana, y son siempre el reflejo de la esencia familiar en el continente, ya que su concepción es casi uniforme en toda África (de norte a sur y de oriente a occidente).

En realidad, la familia en África negra, hoy como en el pasado, se extiende desde el núcleo restringido (padres-hijos) hasta el engranaje del parentesco donde las costumbres y los lazos tradicionales se conjugan para formar un sistema conexo e indisoluble (Ki-Zerbo, 1972, p. 22). A pesar de la idea ampliamente difundida de que en África los lazos y los roles familiares son exclusivamente naturales (definidos por la sangre), en realidad van más allá de los lazos de sangre, ya que son construcciones histórico-sociales que implican una acción intelectual que la sociedad hace de sí misma (Göran, 2004; Makiwane y Chammah, 2018). Esta vertiente, durante mucho tiempo incluso, había sido negada por algunos sociólogos occidentales, sobre todo franceses (Mappa, 1998, p. 19).

En efecto, la historia y la dinámica en las cuales se inscribe la familia en África negra en general son diferentes a las de la sociedad occidental. En Europa, la dinámica de la familia nuclear se radicalizó a finales del siglo XIX y quedó marcada por la separación de los cónyuges respecto a su familia de origen, y afirmó, asimismo, la independencia absoluta de la nueva estructura familiar en relación con los padres, ascendientes y laterales. En este modelo occidental, las funciones de los diferentes miembros de la familia están claramente definidas y muy limitadas. No hay confusión posible entre el papel de los abuelos, el de los padres y el de los hijos. De igual manera, quedan bien marcadas las diferencias entre padres, tíos e hijos. 
Sin embargo, este proceso de individualización, nuclearización y exclusión paulatina que se ha producido en la familia occidental nunca se ha dado en África negra. En efecto, mientras que en Europa se ha definido con claridad la transición del orden familiar tradicional al moderno (patriarcal, individualista e igualitario), en África el sistema de parentesco queda relativamente indiferenciado en cuanto al sexo, las generaciones y las clases sociales.

Este fenómeno adquiere relevancia y complejidad a partir del momento en que se le agrega el papel actual de la mujer en la familia negroafricana. Tanto en las aldeas como en las ciudades, la mujer puede ingresar en el mercado laboral en cualquier etapa de la vida familiar, y ello le permite tener mayores expectativas de satisfacción personal a través del matrimonio, más allá del machismo presente en muchas tribus y etnias en África negra tradicional.

No hay que perder de vista que la familia es el principal lugar de socialización del individuo y que la figura de la mujer es de suma importancia en este proceso. Los valores que el hogar inculca en el sujeto (confiar en sí mismo, ser libre y fraternal...) son herramientas para que aprenda a conquistar su independencia no sólo respecto al resto de la sociedad en que se desenvuelve, sino también ante sí mismo y su propia familia.

Es importante reconocer que, hoy en día, la familia africana ha variado en relación con su forma más tradicional en cuanto a funciones, composición, ciclo de vida y rol de los padres. El cometido que antes desempeñaba la familia rural (trabajo, educación, formación religiosa, actividades de recreo y socialización de los hijos) ahora lo completan instituciones especializadas. El trabajo se realiza normalmente fuera del grupo familiar y los miembros suelen tener ocupaciones diferentes lejos del hogar. El Estado y las iniciativas privadas proporcionan gran parte de la educación. A pesar de ello, la dinámica histórica en la cual se inscribe la familia negroafricana se rige por los principios de respeto a los lazos tradicionales, 
estrechamente relacionados con los ancestros. Eso significa que la filiación ancestral es una obligación que preside toda relación familiar y amplía su campo de acción en los procesos de construcción comunitaria.

\section{El clan como extensión de la familia africana}

Ahora bien, en África negra tradicional varias familias con un antepasado común forman el clan, es decir, la familia se articula en una sociedad más amplia mediante grupos de parentesco definidos por el lazo sanguíneo. Algunos antropólogos utilizan el concepto de "clan" para referirse a diversos grupos de pueblos indígenas de cualquier parte del mundo. En África negra, el clan representa un grupo de familias cuyos miembros apelan a un antepasado común (Tort y Desalmand, 1978; Touoyem, 2014; Bagayoko y Rodrigue, 2017). En este caso, el clan describe a un grupo de personas capaces de reconocer su descendencia respecto de un antepasado común, o que se identifican con un tótem o animal común. La pertenencia a un clan implica la solidaridad social, es decir, la obligación de prestarse ayuda mutua y de participar en ritos, costumbres y ceremonias comunes.

Es justamente a partir del clan que se empieza a percibir el sentido de comunidad en África negra tradicional. En efecto, dentro de un clan que, desde una visión macrosocial, es concebido como un subsistema, existe un andamiaje de leyes ante las cuales todos los miembros de las diferentes familias tienen las mismas obligaciones y los mismos derechos. Si bien en el sistema tradicional negroafricano estas leyes no son explícitamente escritas en un código formal, se aplican en función del rango que cada individuo ocupa en las jerarquías familiares. Esto implica, por un lado, el deber del hombre y la mujer (cada uno con sus funciones específicas) de velar por el bienestar integral de las familias. Mappa Sofia (1998, p. 51) considera que, por otro lado, el clan genera derechos, ya que "todos los miem- 
bros de esas comunidades tienen derecho a la tierra, a la comida y a la solidaridad".

Como se mencionó, la plataforma que le da unidad al clan es el antepasado común; no obstante, por ningún motivo el clan se puede considerar una "unidad utilitaria", capaz de movilizar las fuerzas de todos sus miembros cuando ciertas tareas colectivas lo requieran; más bien, es el lugar donde el niño negroafricano es iniciado progresivamente en los misterios de la naturaleza, de su historia y de los espíritus. Por tales razones, la formación humana en el seno del clan tiende a ser severa y normativa, ya que el niño debe mostrar en todo momento un profundo respeto y temor hacia los adultos.

Es de resaltar que, en la vida comunitaria dentro de un clan en África negra, cada miembro tiene la obligación de protagonizar la prosperidad colectiva, tal y como lo indican los lineamientos de las costumbres. Desde esta perspectiva, las ventajas personales, los intereses y las iniciativas individuales se integran a los imperativos regidos por la sobrevivencia colectiva. Del mismo modo, la necesidad de una cohesión interna de la comunidad - que asegura el respeto del patrimonio indivisible legado por los ancestros- se explica por la prevalencia de un poder único que se ejerce sobre cada individuo para privilegiar la prosperidad general y el respeto de las costumbres. Esto nos lleva a analizar la organización social en África en un nivel superior, materializado por la tribu y la etnia.

\section{El paradigma étnico-tribal: manifestación del dinamismo comunitario}

En el contexto negroafricano no es muy cómodo ni correcto diferenciar etnia y tribu, ya que ambos conceptos hacen referencia a una misma realidad sociológica. Fue justamente el reduccionismo colonial ${ }^{5}$ el que indujo a este tipo de distinción.

${ }^{5}$ En este marco, sostengo que ese "reduccionismo colonial" no ha sido otra 
En efecto, cuando los europeos hablan de lapones, frisones, bretones, flamencos, bávaros, corsos, etc., consideran que son etnias europeas. En cambio, cuando se habla de tutsis, hutus, umbundus, mandingos, masáis, twas, ewondo, baholes, se dice que son tribus africanas.

De igual manera, de una personalidad pública europea se dirá que es de ascendencia escocesa o vasca, pero del presidente de un Estado africano se dirá que pertenece a la tribu shosa, kikuyu, bamileke, etc. Juan Manuel Cabezas (2004, pp. 31-34) considera que esto es resultado de la estratificación europea de los componentes de la sociedad, donde el término "tribu" encierra una carga peyorativa porque se relaciona con primitivismo, irracionalidad y violencia, en comparación con el concepto de etnia.

En el marco de este artículo, lejos de asumir un compromiso en el debate sobre por qué en Europa hay etnias y en África tribus, me interesa abordar estas categorías sociales desde el punto de vista de su dinámica funcional en África negra. $\mathrm{Nu}$ merosos antropólogos y etnólogos han intentado estratificar la sociedad africana; y algunos han dejado de usar el concepto de tribu "por su poca capacidad explicativa" (Godelier, 1974, pp. 198-200). Exploradores, soldados, misioneros y viajeros en general aplicaron su criterio particular para especificar a cualquier grupo que parecía diferente de los otros. Se contaron y se catalogaron miles de grupos étnico-tribales, de tal modo que hoy en día, como lo menciona Massimango (1992), la mera definición del término etnia, por ejemplo, ha provocado numerosas discusiones en el medio de las ciencias sociales. Cada uno de estos conceptos se utiliza en función de los intereses y los objetivos del analista, pero en el fondo significan lo mismo: "grupos humanos ligados por la sangre, los antepasados, el lenguaje, historias y formas de vida propias, etc.; y aún lo están

cosa sino un acercamiento inferiorizante y racista a la realidad negroafricana. Pues el racismo ha inferiorizado al negro, al indígena... de ahí, las organizaciones sociales africanas recibieron despectivamente la categoría de "tribu", esto es, organizaciones aún no avanzadas para ser "etnias" o "grupos sociales". 
mucho más por el vínculo que tienen ellos mismos en relación con los demás" (Espinoza, 2012; Abe, 2011).

Esto significa que, en África negra, los términos etnia y tribu se refieren a colectivos diferenciados de otros colectivos vecinos por determinadas características de tipo cultural, racial, lingüístico, etc. Ambas realidades son representativas de la expansión de un conjunto de clanes. Ahí no aparece ninguna disparidad entre tribu y etnia. A veces (y con muchas reservas), se distingue una de otra por el número de sus miembros: ${ }^{6}$ las etnias estarían compuestas por una gran población, y las tribus, por grupos humanos reducidos. Massimango (1992, p. 167) considera las etnias como grupos socioculturales organizados, conscientes de su existencia y cuyos miembros presentan ciertas características comunes, de tal modo que se distinguen de los miembros de otros grupos con rasgos de pertenencia diferentes de los suyos. Esto significa que la etnia en África describe o designa un conjunto de individuos que posee algún grado de cohesión y solidaridad, es decir, no es una sencilla sumatoria de gente o un sector de la población, sino un grupo autoconsciente de personas unidas o estrechamente relacionadas por experiencias compartidas.

Asimismo, los atributos que se admiten para caracterizar los grupos étnicos africanos son: i) conglomerado social capaz de reproducirse biológicamente; ii) que reconoce un origen común; iii) cuyos miembros se identifican entre sí como parte de un "nosotros" distinto de los "otros" (que son miembros de grupos diferentes de la misma clase) e interactúan con éstos a partir del reconocimiento recíproco de la diferencia, y iv) que comparten ciertos elementos y rasgos culturales, entre los que tiene especial relevancia la lengua (Mballa, 2011a, p. 258).

${ }^{6}$ Cabe mencionar que el factor número no es determinante para diferenciar la tribu de la etnia. Por ejemplo, vemos que los hausas en África son más de 27 millones de personas (más que la población de la mayoría de los países europeos) y son considerados una tribu, mientras que los frisones, con una población inferior al millón de personas, son considerados una minoría étnica europea. 
Lo más notable es que las tribus o etnias africanas se caracterizan por un alto grado de etnicidad. Por etnicidad me refiero a una cualidad étnica que implica la afiliación y la conciencia de pertenecer a un grupo étnico, lo que es determinante para la caracterización de la cultura en África negra. Como se aprecia, gran parte de la actividad cultural africana y de construcción comunitaria se centra en el individuo, en la familia y en el dinamismo étnico-tribal. El arte, la música y la literatura oral sirven para reforzar las estructuras sociales.

Asimismo, la etnicidad africana como modo de expresión funcional de los diferentes grupos étnicos saca a la luz las prácticas culturales y las perspectivas que distinguen a unos grupos de otros. En este sentido, Catherine Coquery-Vidrovitch (1994, p. 4) estima que se trata de "la conciencia de pertenencia a una comunidad lingüística, cultural y política heredada de un pasado común (precolonial)". En la medida en que los miembros de un grupo étnico negroafricano interactúan entre sí, la etnicidad se convierte en el medio por el cual su cultura es transmitida; por lo tanto, la etnicidad se vuelve una manera, para cada negroafricano en su individualidad, de identificarse y sentirse parte de una comunidad frente a otras (Zagefka, 2009, p. 229).

En efecto, los miembros de las entidades étnicas negroafricanas se ven a sí mismos como culturalmente unidos, pero diferentes por las características endógenas de cada una de las comunidades étnicas. Muchas características pueden servir para distinguir a unos grupos étnicos de otros, pero las más usuales son la lengua, la historia, el linaje (real o imaginado), la religión y los estilos de adorno. Hoy en día, aunque nos pueda ser útil clasificar las etnias africanas en bantúes, nilóticas o sudanesas, la verdad es que, cuanto más se estudian, más se descubre lo mezcladas que están sus procedencias ancestrales. De alguna manera, todas han asimilado elementos que han reforzado la característica fundamental de la comunidad en el universo negroafricano, que oscila entre la unidad esencial y la diversidad cultural. 


\section{Consideraciones finales}

En fin, el concepto de comunidad, como hemos visto, merece vestirse de un contenido contextual para cuestiones de claridad en cualquier paradigma de las ciencias sociales. Esto permite saber si una comunidad constituye, en sus intenciones, presupuestos y campo de extensión, una herramienta de análisis satisfactoria que permita entender las dinámicas de las sociedades. En estas condiciones, ni la polisemia del concepto ni la dimensión poliparadigmática de las ciencias sociales son un problema, lo que nos aleja del planteamiento de Theodor Geiger, que propuso que la palabra "comunidad" fuera borrada del lenguaje de las ciencias sociales. Pretender deshacerse del concepto de comunidad sería una negación del carácter profundamente histórico de las ciencias sociales, cuyas disciplinas siempre han encontrado una forma de orientar sus enfoques teórico-conceptuales.

Asimismo, la noción de comunidad en el universo negroafricano se erige sobre toda la herencia sociocultural, económica y política de África negra tradicional a través de una implicación directa de las variables de la persona humana, de la familia, del clan, etc. En efecto, las estructuras que rigen nuestras vidas son, en última instancia, teorías asentadas en nuestras cabezas. Los rasgos definitorios de la vida, la democracia, la vecindad, el panafricanismo, la soberanía, el capitalismo, la pobreza, las minorías, las guerras y los conflictos interétnicos e interestatales tienen sus manifestaciones concretas, pero son esencialmente la culminación de las ideas que se han generado. La idea de comunidad en el sentido negroafricano manifestado aquí es un planteamiento que vislumbra la posibilidad de un cambio progresivo e indispensable para África.

Es una proyección compartida de un África negra, una y múltiple a la vez, que externa la necesidad de construir una coparticipación entre los actuales gobiernos y las capas de la sociedad, en particular de las mujeres, los jóvenes y el sector privado, con el fin de reforzar la solidaridad y la cohesión en- 
tre los pueblos africanos. Con base en esta visión comunitaria (interafricana, panafricana, transafricana, etc.), los africanos y las africanas han de considerarse como un pueblo consciente de la urgencia de situar los intereses colectivos antes que los particulares.

El desafío está en conseguir que los actores que convergen en África reconozcan que aprovechar las ventajas de un pasado compartido (incluso los conflictos) es en parte garantía de un "futuro compartido". Considerar y aprovechar las lecciones de convivencia comunitaria en África negra, en África precolonial $\mathrm{y}$ en las aldeas tiene un papel importante en el proceso de transformación actual.

Asimismo, hace falta una verdadera cura de desintoxicación ante la prospectiva occidental de comunidad, ya que ésta suele ser la principal causa del olvido de los modos de organización comunitaria en África negra tradicional, donde se encuentran las dimensiones del "compartir". Guardando las distancias respecto al actual eurocentrismo, se pueden repensar esos modos de organización comunitaria en toda su diversidad y complementariedad. Al adoptar un mecanismo de "compartir la totalidad de las especificidades", es posible construir un modelo claro de complementariedad en el cual converjan las especificidades de varios tipos de actores africanos y foráneos. Con esta perspectiva de la visión comunitaria en África negra, encontramos un paradigma de comunidad original que podría ser un ecosistema de valores o una praxis de la dinámica intercultural.

\section{Referencias}

ABE, C. (31 de mayo de 2011). Rapport du cafe gouvernance du 27 mai : État et ethnie : entre identités communautaires et identification national comment construire l'unité? Yaundé: Institut pour la Gouvernance en Afrique Centrale. Recuperado de https://base. afrique-gouvernance.net/docs/ethnie_et_etat.pdf 
Adonon, F. (2003). Colonización y en busca del Estado nación y democracia. México: Universidad Nacional Autónoma de México.

Adonon, F. (Coord.) (2012). La otra África. México: Universidad Nacional Autónoma de México.

Adotevi, S. (1996). Les facteurs culturels de l'intégration économique et politique en Afrique. En L. Real (Dir.), Intégration et coopération régionales en Afrique de l'Ouest (pp. 81-94). París: Karthala. Recuperado de https://idl-bnc-idrc.dspacedirect.org/bitstream/handle/10625/15221/IDL-15221. pdf? sequence $=1 \&$ isAllowed $=y$

Alliot, M. (1985). La coutume dans les droits originellement africains. Bulletin de liaison du LAJP, (7-8), 79-100.

Alliot, M. (2000). Un passeur entre les mondes: le livre des anthropologues du droit, disciples et amis du recteur Michel Alliot. París: Publications de la Sorbonne.

Alliot, M. (2003). Religions d'Afrique et droit d'expression français. En C. Kuyu (Ed.), Le droit et le service public au regard de l'anthropologie (pp. 53-71). París: Karthala.

Azombo, M. (1971). Séquences et signification des cérémonies d'initiation So. (Tesis doctoral). Université de la Sorbonne, París.

BAgAYOKO, N. y Rodrigue K., F. (2017). Les mécanismes traditionnels de gestion des conflits en Afrique subsaharienne (Rapport de recherche 2). Québec: Centre FrancoPaix en résolution des conflits et missions de paix. Recuperado de https://dandurand.uqam.ca/ publication/les-mecanismes-traditionnels-de-gestion-des-conflitsen-afrique-subsaharienne/

BALANDIER, G. (1995). Sociologie actuelle de l'Afrique noire : dynamique sociale en Afrique Centrale. París: Presses Universitaires de France.

Boudon, R. y Bourricaud, F. (1986). Dictionnaire critique de la sociologie. París: Presses Universitaires de France.

Busino, G. (1993). Qu'est-ce que la communauté selon les sociologues? En Autor, Critiques du savoir sociologique (pp. 135-152). París: Presses Universitaires de France.

Cabezas, J. M. (2004). Etnosistemas afroamericanos. En G. D. Corte (Coord.), Relaciones sociales e identidades en Ámerica (pp. 31-43). Barcelona: Universitat de Barcelona. E-book recuperado de https://dallacorte.wordpress.com/2013/07/25/libro-relaciones- 
sociales-e-identidades-en-america-ix-encuentro-debate-americalatina-ayer-y-hoy/

Cabral, A. (1975). Unitéet lutte I. L'arme de la théorie. París: Maspero. Castañeda, G. R. (2016). Familia y mestizaje en dos cofradías de descendientes de africanos en Nueva España (San Miguel el Grande, siglo XVIII). Trace, (69), 96-120. https://doi.org/10.22134/ trace.69.2016.11

CheIKH, A. D. (1974). Les fondements économiques et culturels d'un État fédéral d'Afrique noire. París: Présence Africaine.

Coquery-Vidrovitch, C. (julio de 1994). Du bon usage de l'ethnicité. Le Monde diplomatique, 4-5. Recuperado de https://www.mondediplomatique.fr/1994/07/COQUERY_VIDROVITCH/7336

EBErhard, C. (2002). Droits de l'homme et dialogue interculturel. París: Éditions des écrivains.

EsPINOZA, M. D. (2012). La gran escuela de la vida: el papel de la tradición oral en la educación africana. En F. Adonon, La otra África (pp. 39-55). México: Universidad Nacional Autónoma de México. FAÏK-NZUjI, C. (1993). La puissance du sacré: l'homme, la nature et l'art en Afrique noire. Bruselas: Renaissance du Livre.

FANON, F. (1961). Les damnés de la terre. París: La Découverte. Recuperado de https://monoskop.org/images/9/9d/Fanon_Frantz Les_damn\%C3\%A9s_de_la_terre_2002.pdf

GeIger, T. (1932). Die soziale Schichtung des deutschen Volkes: Soziographischer Versuch auf statistischer Grundlage. Stuttgart: Enke.

GODELIER, M. (1974). Economía, fetichismo y religión en las sociedades primitivas. México: Siglo XXI.

GörAn, T. (Ed.) (2004). African families in a global context. Upsala: Nordiska Afrikainstitutet. Recuperado de http://www.divaportal.org/smash/get/diva2:240546/FULLTEXT02.pdf

GuÉRIN, F. (2004). Le concept de communauté : une illustration exemplaire de la production des concepts en sciences sociales? Ponencia presentada en la $13^{\text {ème }}$ Conférence de l'Association International de Managment Stratégique, Vallée de SeineNormandie, 2, 3 et 4 juin. Recuperado de https://www. strategie-aims.com/events/conferences/10-xiiieme-conferencede-l-aims/communications/458-les-lecons-de-management-dela-communaute-linux/download

Gutiérrez A., R. (2017). Horizontes comunitario-populares. Producción de lo común más allá de las políticas estado-céntricas. Madrid: 
Traficantes de Sueños. Recuperado de https://www.traficantes. net/sites/default/files/pdfs/Horizontes\%20comunitario-populares_Traficantes\%20de\%20Sue\%C3\%B1os.pdf

Hagenbucher-S., F. (1973). Les fondements spirituels du pouvoir au royaume de Loango, République Populaire du Congo. París: Office de la Recherche Scientifique et Technique Outre-Mer. Recuperado de http://horizon.documentation.ird.fr/exl-doc/ pleins_textes/divers4/06702.pdf

Hillery Jr., G. A. (1955). Definitions of community: Areas of agreement. Rural Sociology, 20(2), 111-123.

Hillery Jr., G. A. (1982). A research odyssey: Developing and testing a community theory. Nuevo Brunswick, NJ: Transaction Books.

Ki-Zerbo, J. (1972). Contribution du génie de la femme à la civilisation négro-africaine. En La civilisation de la femme dans la tradition africaine, actas del coloquio organizado por la Société Africaine de Culture, Abidjan, 3-8 de julio (pp. 19-29). París: Présence Africaine.

Ki-Zerbo, J. (2003). Le développement clés en tête. En F. Adonon (Coord.), ¿África boy? (pp. 201-296). México: Universidad Nacional Autónoma de México.

LAAKo, H. (2014). Más allá del centro y la periferia: la frontera sur de México a debate desde la globalización. Revista Pueblos y Fronteras Digital, 9(18), 5-18. https://doi.org/10.22201/ cimsur.18704115e.2014.18.19

LALEYE, I. P. (1970). La conception de la personne dans la pensée traditionnelle Yoruba: "approche phénoménologique". Berna: Herbert Lang.

Le Roy, E. (1999). Le jeu des lois : une anthropologie 'dynamique' du droit. París: LGDJ.

Makiwane, M. y Chamah, J. K. (15 de mayo de 2018). Families and inclusive societies in Africa. Ponencia presentada en la conferencia 2018 International Day of Families. Nueva York, NY: United Nations. Recuperado de https://www.un.org/development/ desa/family/wp-content/uploads/sites/23/2018/05/1-2.pdf

Mappa, S. (1998). Pouvoirs traditionnels et pouvoir d'État en Afrique: l'illusion universaliste. París: Karthala.

Massimango, C. K. (1992). Etnicidad y pluralismo político en el África negra. En C. Agüero Doná (Coord.), África: inventando el futuro (pp. 167-181). México: El Colegio de México. 
Mballa, L. V. (2008). El Estado africano: entre crisis y conflictos. Razón y Palabra, (62), 3-15. Recuperado de http://www.razonypalabra.org.mx/n62/lmballa_m.html

Mballa, L. V. (2011a). Construcción comunitaria en África: obstáculos $y$ perspectivas. Saarbrücken: Editorial Académica Española.

Mballa, L. V. (2011b). Dimensión comunitaria de la persona en el universo tradicional negroaficano. En B. Bolaños y M. Madureira (Eds.), Autoconocimiento y reflexividad: perspectivas contemporáneas (pp. 241-269). México: Universidad Autónoma Metropolitana, Cuajimalpa.

M’BoкоLo, E. (1980). L'Afrique au XX siecle : le continent convoité. París: Études vivantes.

MinaR, D. W. y Greer, S. (Eds.) (1969). The concept of community: Readings with interpretations. Chicago, IL: Aldine.

Minuchin, S. (1979). Familles en thérapie. París: Delarge.

Moreau de Bellaing, L. (1990). Sociologie de l'autorité. París: L'Harmattan.

Mveng, A. (1966). Introduction. En G. H. Rivière y A. Mveng, L'art nègre. Sources, évolution et expansion: exposition organisée au Musée Dynamique à Dakar par le Commissariat du Festival mondial des arts nègres et au Grand Palais à Paris. París: Réunion des Musées Nationaux Français.

Ocholla-Ayayo, A. B. C. (1999). La famille africaine entre tradition et modernité. En Aderanti Adepoju (Ed.), La famille africaine : politiques démographiques et développement (pp. 85-108). París: Karthala.

PAsseron, J.-C. (1991). Le raisonnement sociologique : l'espace nonpoppérien du raisonnement naturel. París: Nathan.

Poplin, D. E. (1972). Communities: A survey of theories and methods of research. Nueva York, NY: Macmillan.

REYNÉs, R. M. (2012). Familias y sistemas educativos en África negra. Foro de Educación, 10(14), 115-130. Recuperado de https://www. forodeeducacion.com/ojs/index.php/fde/article/view/3/3

SANZ, E. (2010). Estadocentrismo, sociocentrismo y estatismo en la construcción de paz posbélica. Postbélica Post, (1), 3-16. Recuperado de https://ddd.uab.cat/pub/estudis/2010/71728/post. dis.01.07.2010.sanz.estadocentrismo.pdf

SCHERER, J. (1972). Contemporary community: Sociological illusion or reality? Londres: Tavistock Publications. 
Senghor, L. S. (1964). Négritude et humanisme. París: Seuil. Sow, I. (1977). Psychiatrie dynamique africaine. París: Payot. TorT, P. y Désalmand, P. (1978). Sciences humaines et philosophie en Afrique: la différence culturelle. París: Hatier.

Touoyem, P. (2014). Dynamiques de l'ethnicité en Afrique : éléments pour une théorie de l'État multinational. Camerún: Langaa.

Tsala-Tsala, J. P. (1989). De la demande thérapeutique au Cameroun. Revue de Médecine Psychosomatique, (19), 109-124.

Valdivia S., C. (2008). La familia: concepto, cambios y nuevos modelos. La Revue du REDIF, 1, 15-22.

Verschave, F. X. (marzo de 1995). Autopsie d'un génocide planifié : Connivences françaises au Rwanda. Le Monde-diplomatique, p. 10. Wilhelmy, M. (1988). Política internacional: enfoques y realidades. Buenos Aires: Grupo Editor Latinoamericano.

ZAGEFKA, H. (2009). The concept of ethnicity in social psychological research: Definitional issues. International Journal of Intercultural Relations, 33(3), 228-241. https://doi.org/10.1016/j. ijintrel.2008.08.001

Louis Valentin Mballa es licenciado en economía por la Universidad de Douala (Camerún), y en filosofía por el Instituto de Filosofía San José Mukasa de Yaundé (Camerún), así como maestro en relaciones internacionales y doctor en ciencias políticas por la Universidad Nacional Autónoma de México. Es profesor-investigador en la Facultad de Contaduría y Administración de la Universidad Autónoma de San Luis Potosí. Es secretario ejecutivo de la Red Internacional de Investigadores en Ciencias de Gestión y presidente de la Asociación de los Cameruneses en México. Pertenece al Sistema Nacional de Investigadores, nivel I, del Consejo Nacional de Ciencia y Tecnología, México.

https://orcid.org/0000-0001-9082-9055 luigivaldo@hotmail.com 